\title{
Vertebral fracture and splenomegaly in a head and neck cancer producing granulocyte colony-stimulating factor: A case report of systemic complications associated with a cytokine-producing solid tumor
}

\author{
NAOYA KITAMURA ${ }^{1}$, SHINYA SENTO ${ }^{1}$, ERI SASABE ${ }^{1}$, KATSUHITO KIYASU $^{2}$, \\ KOSUKE NAKAJI ${ }^{3}$, MASANORI DAIBATA $^{4}$ and TETSUYA YAMAMOTO ${ }^{1}$ \\ Departments of ${ }^{1}$ Oral and Maxillofacial Surgery, ${ }^{2}$ Orthopedic Surgery, ${ }^{3}$ Radiology, and \\ ${ }^{4}$ Microbiology and Infection, Kochi Medical School, Kochi University, Kochi 783-8505, Japan
}

Received March 3, 2021; Accepted June 15, 2021

DOI: $10.3892 / \mathrm{mco} .2021 .2364$

\begin{abstract}
Granulocyte colony-stimulating factor (G-CSF)producing tumors are rare and are associated with a poor prognosis when they occur in the lungs and the head and neck region. Positron emission tomography/computed tomography has been reported to show systemic specific accumulation of fluorodeoxyglucose in these cases, but the systemic complications associated with the cytokines produced are not well known. We herein present the case of a G-CSF-producing maxillary sinus squamous cell carcinoma in a 73-year-old Japanese woman with a vertebral fracture and splenomegaly. These findings are known severe adverse events of high-dose recombinant human G-CSF treatment. The aim of the present study was to further discuss the hypothesis that cytokines produced by solid tumors may induce spinal vertebral fracture and splenomegaly.
\end{abstract}

\section{Introduction}

Granulocyte colony-stimulating factor (G-CSF)-producing tumors of the lungs and head and neck region are rare, and they are associated with a poor prognosis $(1,2)$; however, the

Correspondence to: Dr Naoya Kitamura, Department of Oral and Maxillofacial Surgery, Kochi Medical School, Kochi University, Kohasu, Oko-cho, Nankoku-shi, Kochi 783-8505, Japan

E-mail: nkitamura@kochi-u.ac.jp

Abbreviations: G-CSF, granulocyte colony-stimulating factor; rhG-CSF, recombinant human G-CSF; FDG, fluorodeoxyglucose; $\mathrm{PET} / \mathrm{CT}$, positron emission tomography/computed tomography; WBC, white blood cell; CRP, C-reactive protein; CCRT, concomitant chemoradiotherapy; BNCT, boron-neutron capture therapy; ALP, alkaline phosphatase; BSC, best supportive care

Key words: granulocyte colony-stimulating factor, vertebral fracture, splenomegaly, complication, head and neck cancer systemic complications due to the cytokines produced by the tumor are not well known. The adverse events of recombinant human G-CSF (rhG-CSF) administered to mobilize peripheral blood stem cells include spinal bone pain and osteoporosis (with vertebral fractures in severe cases), myocardial infarction, stroke and splenomegaly (with splenic rupture in severe cases). It has been reported that G-CSF signaling induces osteoporosis by activating osteoclasts through suppression of osteoblast activity (3-6). Furthermore, the abnormal accumulation of fluorodeoxyglucose (FDG) in the red bone marrow on positron emission tomography/computed tomography (PET/CT) is attributed to the enhancement of glucose metabolism by the increased hematopoietic capacity of the granulocyte system of the bone marrow induced by G-CSF (7-9). Although several cases of solid cancers, such as lung cancer and head and neck cancer, that produce G-CSF with abnormal FDG accumulation on PET/CT have been published, no systemic complications have been reported to date $(10,11)$. A case of a suspected pathological fracture of a lumbar vertebra and splenomegaly associated with G-CSF cytokine production by maxillary sinus squamous cell carcinoma (SCC) is described herein. This mechanism is similar to the clinical conditions when high-dose rhG-CSF is administered. Therefore, the aim of the present study was to further examine the hypothesis that cytokines produced by solid tumors may induce vertebral fractures and splenomegaly.

\section{Case report}

A 73-year-old Japanese woman was referred to the Kochi Medical School Hospital (Kochi, Japan) in August 2018, with a complaint of painful swelling on the right side of the maxillary gingiva for the last month. The patient's history included osteoporosis, for which she received conservative treatment following a fracture at the 3rd lumbar vertebra (L3) in 2008, and had been receiving risedronate hydrate $(17.5 \mathrm{mg} /$ week) since 2014. Her family history was unremarkable. On a regular medical examination by a local internal medicine specialist, the patient was found to have an increased white blood 
cell (WBC) count $(50,100 / \mu 1$; normal range: 3,300-8,600/ $\mu \mathrm{l})$ and elevated C-reactive protein (CRP) levels $(3.98 \mathrm{mg} / \mathrm{dl}$; normal value: $\leq 0.14 \mathrm{mg} / \mathrm{dl}$ ).

The initial examination revealed a painful swelling with redness extending from the gingival-cheek junction on the right side of the maxilla to the palate, and maxillary CT examination revealed a uniform low-density area occupying the right maxillary sinus (Fig. 1A and B). Biopsy was performed under the provisional diagnosis of a maxillary sinus tumor. The histopathological diagnosis was poorly differentiated SCC, and immunohistochemical staining for anti-G-CSF antibody was positive (Fig. 1C and D). Based on these results, the patient was diagnosed with a G-CSF-producing SCC of the maxillary sinus (TNM classification: cT3NOMx). Chemoradiotherapy was selected as the treatment strategy, avoiding extended maxillary resection. After the biopsy, the WBC count decreased $(9,800 / \mu 1)$, but it increased again 1 month later $(125,300 / \mu 1)$, so concomitant superselective intra-arterial infusion chemoradiotherapy (CCRT) was scheduled (Fig. 2; Table I). FDG-PET/CT conducted at the same time showed no evidence of distant metastasis in the lungs or liver, but revealed diffuse abnormal accumulation of FDG in the red bone marrow of the whole body, including the spine (Fig. 3). Three days later, the patient suddenly complained of severe lower back pain, and lumbar MRI examination revealed a burst fracture of the L2 vertebra, but no obvious distant bone metastasis was observed (Fig. 4). Subsequently, the patient was treated conservatively with a hard brace for 1 month, while CCRT (cisplatin: Total $650 \mathrm{mg}$; RT: $60 \mathrm{~Gy}$ ) was performed for the maxillary sinus cancer, and the WBC count decreased significantly $(4,400 / \mu 1$ at 1.5 months post-CCRT).

No evidence of spinal metastasis was found for $\sim 2$ years, from the time of the $\mathrm{L} 2$ fracture to the diagnosis of terminal disease (Fig. 5). During that period, the patient underwent boron-neutron capture therapy (BNCT) for recurrence of the primary lesion, selective neck dissection for late neck lymph node metastasis, and nivolumab immunotherapy for distant lung metastasis for $\sim 6$ months (Fig. 2). However, due to the elevated WBC count (131,700/ $\mu$ 1; Fig. 2; Table I), onset of splenomegaly (Fig. 6), decreased performance status, uncontrolled primary tumor and the patient's wishes, she switched to best supportive care (BSC) and she succumbed to the disease 2 years and 2 months after the initial visit.

\section{Discussion}

G-CSF-producing tumors are associated with a poor prognosis, with a mean survival of $<1$ year $(1,2)$. In the present case, however, the patient survived for $>2$ years, as she was able to maintain stable disease with CCRT, BNCT, neck dissection and nivolumab immunotherapy. The patient was also diagnosed with metastatic cervical lymph nodes and distant lung metastases, complained of severe pain at the site of cervical metastasis and requested resection. Therefore, selective neck dissection was performed prior to nivolumab immunotherapy. For head and neck cancer, when distant metastases are identified, various treatment strategies, including BSC, may be selected, taking into consideration the patient's quality of life (12). Selective neck dissection prior to nivolumab immunotherapy has helped maintain the quality of life of the patients, and our approach was among the treatments considered as standard. During the treatment period, the patient's WBC count, serum G-CSF and alkaline phosphatase (ALP) levels followed the same trend, and extremely high values were associated with the occurrence of two systemic complications, namely vertebral fracture and splenomegaly.

The pathological burst fracture of a lumbar vertebra was inferred to be the consequence of G-CSF produced by the maxillary sinus SCC in this elderly patient with osteoporosis, rather than bone metastasis, for the following reasons: First, lumbar MRI of the vertebral fracture (Fig. 4) and FDG-PET/CT examination performed 8 months after the L2 vertebral fracture (upon recurrence of the primary lesion; Fig. 5) revealed no findings suggesting bone metastasis in L2. Furthermore, the L2 vertebral fracture was not of the compression, but rather of the burst type (Fig. 4). Second, FDG-PET/CT performed a few days before the L2 vertebral fracture revealed abnormal diffuse accumulation of FDG in the red bone marrow of the whole body (Fig. 3). These findings are often seen in cases of hematopoietic tumors such as leukemia, malignant lymphoma and multiple myeloma, which are associated with complications such as bone pain and vertebral fractures (7-9). Finally, the patient's WBC count, serum G-CSF, ALP, CRP levels, SCC antigen titer and bone ALP increased sharply at the time of the L2 vertebral fracture (Fig. 2; Table I).

Although the serum Ca level was slightly low $(7.9 \mathrm{mg} / \mathrm{dl}$; normal range: $8.8-10.1 \mathrm{mg} / \mathrm{dl}$ ) after tumor extirpation (prior to the L2 vertebral fracture), no significant changes were observed throughout the treatment period (Table I).

The mechanism by which G-CSF causes fractures is known to be activation of osteoclasts through suppression of osteoblast activity, and there are some reports that bone mineral loss is caused in pediatric patients with congenital neutropenia and hematopoietic tumors (3-6). Furthermore, the abnormal accumulation of FDG in the red bone marrow of the whole body on PET/CT is considered to be due to the enhancement of glucose metabolism caused by the increased hematopoietic activity of the granulocyte system of the bone marrow induced by G-CSF. These FDG-PET findings have been reported in several cases of solid tumors, such as lung cancer and head and neck cancer, that produce G-CSF $(10,11)$, but no spine-related complications have been reported to date. In a case previously reported by Kuroshima et al (11), FDG-PET/CT revealed an L4 vertebral fracture during the treatment period, although there has been no mention of this adverse event in the literature to date; this may have been a vertebral fracture that occurred through the same mechanism as that described in the present study. However, a search through the literature using the PubMed engine revealed no other reports suggesting that G-CSF produced by solid tumors was associated with vertebral fractures.

On the other hand, splenomegaly and splenic infarction have been reported to occur in association with hematological malignancies, infective endocarditis and atrial fibrillation. It is considered that the administration of rhG-CSF preparations may cause splenic rupture or infarction, as platelet aggregation through the recruitment of hematopoietic stem cells into the peripheral blood causes infarction of the intra-splenic vessels $(13,14)$. According to Khinji and 

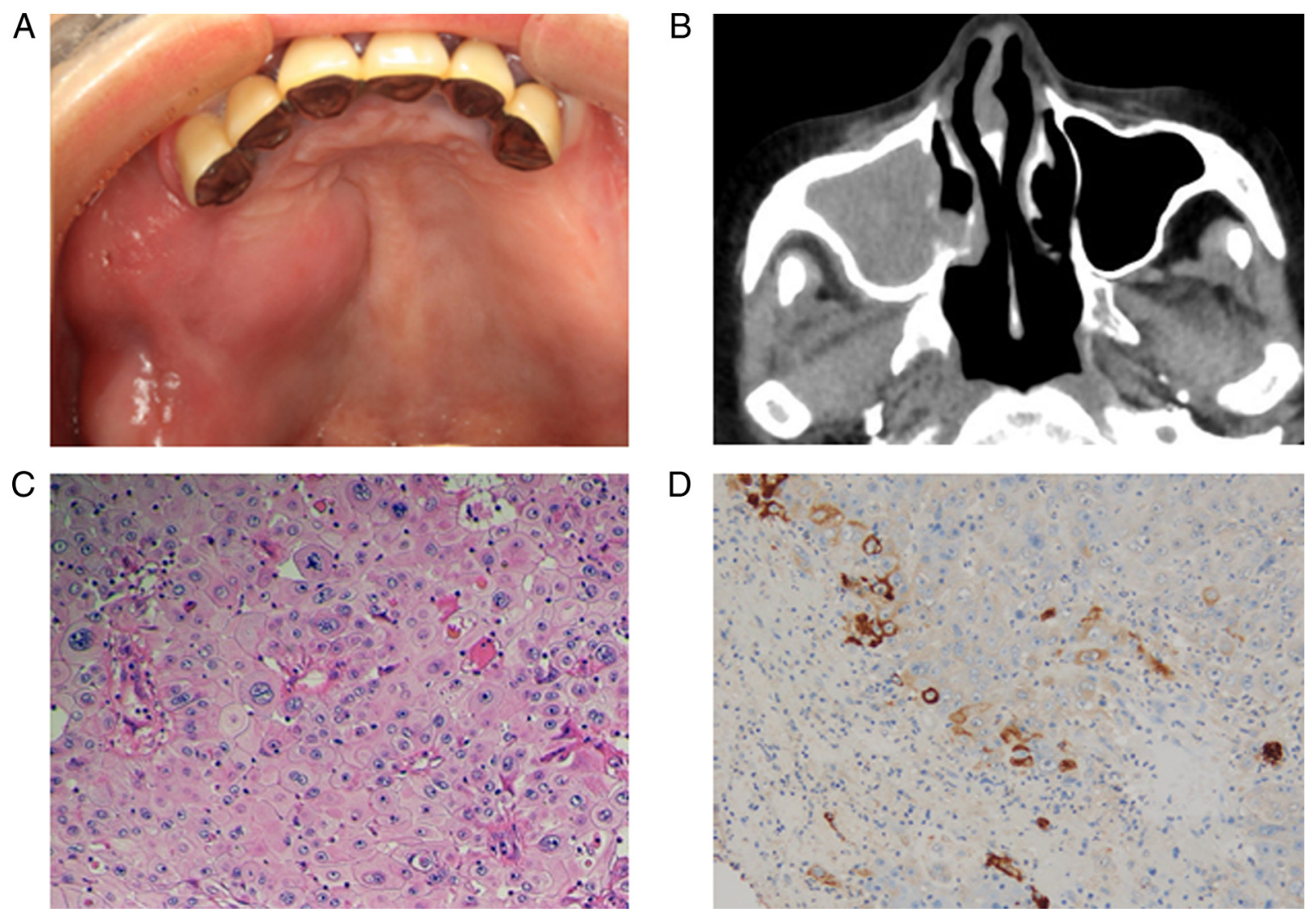

Figure 1. Clinical and histopathological findings. (A) Initial examination revealed a painful swelling with redness extending from the gingival-cheek junction on the right side of the maxilla to the palate. (B) Maxillary CT examination revealed a uniform low-density area occupying the right maxillary sinus. (C) HE staining; magnification, x200. Following histopathological examination of the tumor biopsy specimen, the diagnosis was poorly differentiated squamous cell carcinoma. (D) On immunohistochemical examination (magnification, x100), staining for anti-granulocyte colony-stimulating factor antibody was positive.

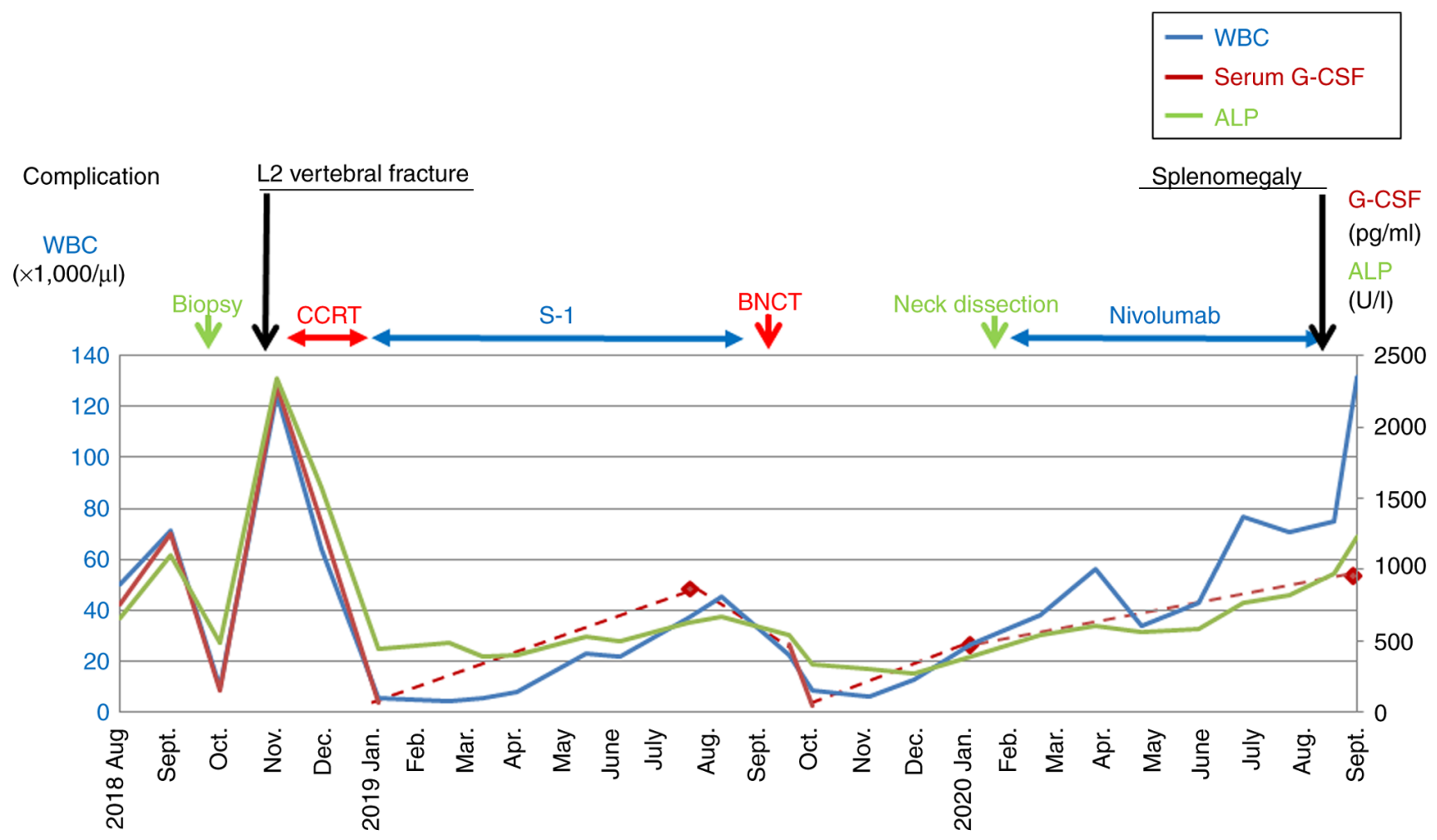

Figure 2. Summary of laboratory findings and clinical course. WBC, white blood cell; CCRT, concomitant chemoradiotherapy; BNCT, boron-neutron capture therapy; G-CSF, granulocyte colony-stimulating factor; ALP, alkaline phosphatase. 
Table I. Laboratory findings.

\begin{tabular}{|c|c|c|c|c|c|c|c|c|}
\hline \multirow[b]{3}{*}{ Findings } & \multicolumn{8}{|c|}{ Year } \\
\hline & \multicolumn{4}{|c|}{2018} & \multicolumn{3}{|c|}{2019} & \multirow{2}{*}{$\begin{array}{c}2020 \\
\begin{array}{c}\text { September } \\
\text { (BSC) }\end{array}\end{array}$} \\
\hline & $\begin{array}{l}\text { September } \\
\text { (Pre-biopsy) }\end{array}$ & $\begin{array}{c}\text { October } \\
\text { (Post-biopsy) }\end{array}$ & $\begin{array}{l}\text { November } \\
\text { (Pre-CCRT) }\end{array}$ & December & $\begin{array}{c}\text { January } \\
\text { (Post-CCRT) }\end{array}$ & $\begin{array}{c}\text { September } \\
\text { (Pre-BNCT) }\end{array}$ & $\begin{array}{c}\text { October } \\
\text { (Post-BNCT) }\end{array}$ & \\
\hline $\begin{array}{l}\text { WBC count } \\
(\mathrm{x} 1,000 / \mu 1)\end{array}$ & 71.1 & 9.8 & 125.3 & 64.1 & 5.3 & 22.6 & 8.6 & 131.7 \\
\hline $\begin{array}{l}\text { G-CSF } \\
(\mathrm{pg} / \mathrm{ml})\end{array}$ & 1,250 & 149 & 2,290 & 1,330 & 65.8 & 480 & 48.7 & 1,010 \\
\hline $\operatorname{ALP}(\mathrm{U} / \mathrm{l})$ & 1,097 & 483 & 2,339 & 1,571 & 449 & 546 & 334 & 1,232 \\
\hline CRP (mg/dl) & 6.5 & 2.37 & 8.91 & 5.45 & 0.68 & 4.46 & 1.19 & 13.92 \\
\hline $\begin{array}{l}\text { SCC Ag } \\
(\mathrm{ng} / \mathrm{ml})\end{array}$ & NA & 4.8 & 25.8 & 3.2 & 1.6 & 2.4 & 1.7 & 30.9 \\
\hline $\mathrm{BAP}(\mu \mathrm{g} / \mathrm{ml})$ & NA & 17.3 & 75 & 30.7 & NA & NA & NA & NA \\
\hline $\mathrm{Ca}(\mathrm{mg} / \mathrm{dl})$ & 9 & 7.9 & 8.9 & 9 & 8.9 & 9.2 & 8.5 & 8.8 \\
\hline
\end{tabular}

WBC, white blood cell; G-CSF, granulocyte colony-stimulating factor; ALP, alkaline phosphatase; CRP, C-reactive protein; SCC Ag, squamous cell carcinoma antigen; BAP, bone ALP; BNCT, boron-neutron capture therapy; CCRT, concomitant chemoradiotherapy; BSC, best supportive care; NA, not available.

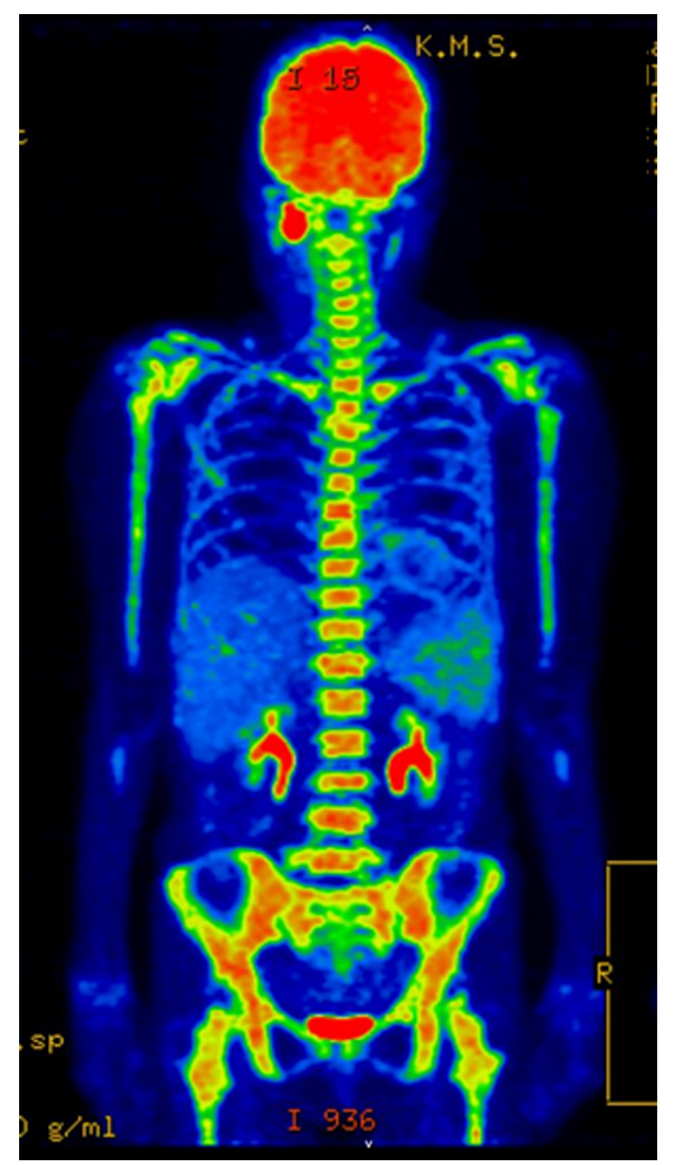

Figure 3. FDG-positron emission tomography findings prior to the L2 vertebral fracture and prior to concomitant chemoradiotherapy. White blood cell count, 125,300/ $\mu \mathrm{l}$; serum granulocyte colony-stimulating factor, 2,290 pg/ml; alkaline phosphatase, 2,339 U/1. Diffuse abnormal accumulations of FDG are observed in the red bone marrow of the whole body, including the spine. Increased FDG uptake from the right side of the maxilla to the palate is also observed. FDG, fluorodeoxyglucose.

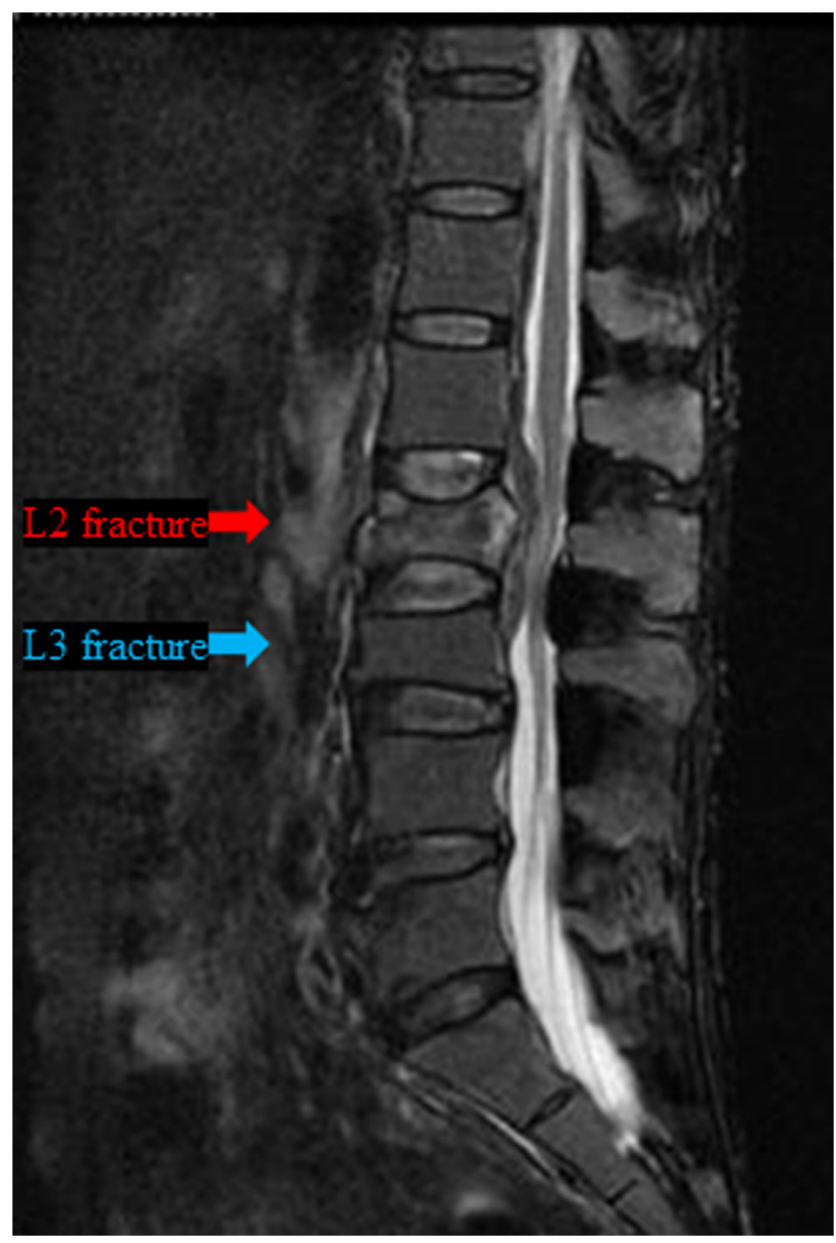

Figure 4. MRI findings of the vertebral fracture on T2 weighted images with fat suppression. High signal intensity is observed in the L2 vertebra. The L2 vertebral fracture is a new fracture of the burst type, whereas the L 3 is an old fracture of the compression type. 


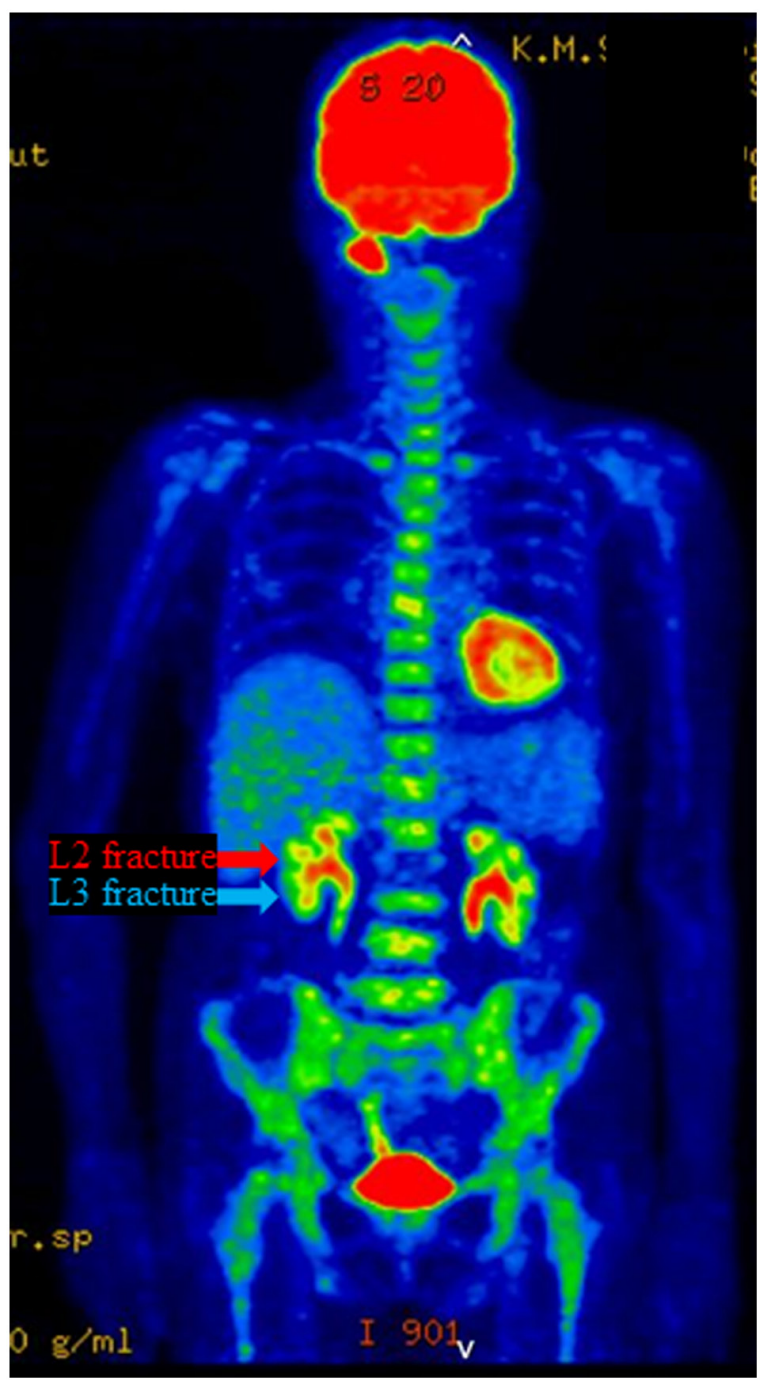

Figure 5. FDG-positron emission tomography findings 8 months after the L2 vertebral fracture (upon recurrence of the primary lesion). White blood cell count, 36,700/ $\mu \mathrm{l}$; serum granulocyte colony-stimulating factor, $875 \mathrm{pg} / \mathrm{ml}$; alkaline phosphatase, $632 \mathrm{U} / 1$. Diffuse abnormal accumulation of FDG in the red bone marrow was found to be decreased. FDG uptake in the L2 vertebra is not observed, whereas increased FDG uptake is observed in the right side of the maxilla (primary lesion). FDG, fluorodeoxyglucose.

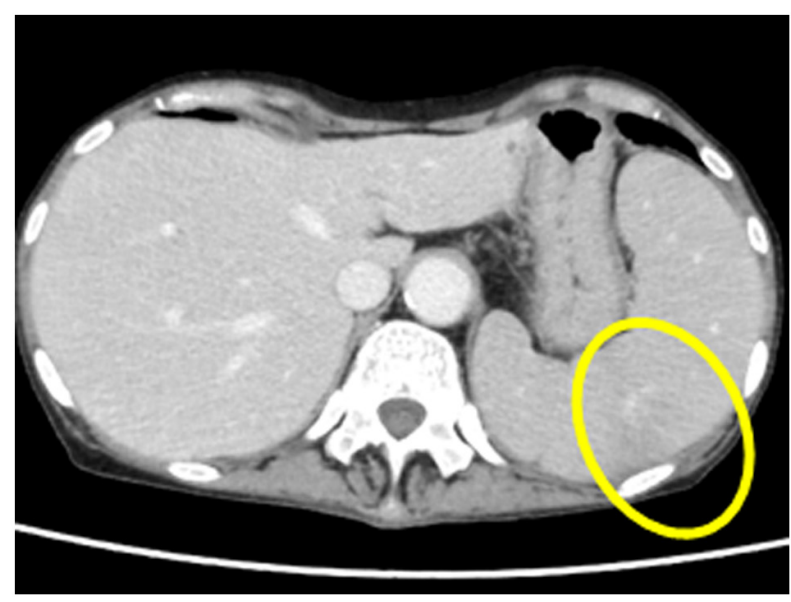

Figure 6. Abdominal contrast-enhanced CT (prior to the transition to best supportive care). A wedge-shaped low-density lesion is observed in the spleen (yellow circle). Exacerbation of splenomegaly and splenic infarction were suspected.
Linenberger (14), of 2,992 cases of adverse events linked to rhG-CSF preparations, 15 (0.5\%) included splenomegaly; in addition, Aubrey-Bassler and Sowers (15) reported that, of 613 cases of splenic rupture, $10(1.6 \%)$ were associated with rhG-CSF preparations. There are several case reports of splenic rupture and infarction when rhG-CSF preparations were administered to patients with cancer for the purpose of treating or preventing myelosuppression by chemotherapy and to healthy donors prior to stem cell transplantation (16-19). However, the PubMed search revealed no reports of splenomegaly hypothetically associated with G-CSF produced by solid tumors, other than the present case and a previously reported case by de Wolff et al (20). The study of de Wolff et al did not report the serum G-CSF levels over time, and there was no evidence that metastatic melanoma produced G-CSF. The authors suspected that melanoma was producing G-CSF as the cause of leukocytosis. Moreover, in their study, the findings of chest and abdominal CT examination suggested lung, liver and spleen metastases; therefore, they did not associate melanoma-produced G-CSF with splenomegaly, unlike our report.

In addition, other previous reports indicated that G-CSF can upregulate the expression of MMPs and can induce cancer cell invasion and metastasis (21-23). Therefore, in the present case, G-CSF-related complications may include not only vertebral fracture and splenomegaly, but also lung metastasis.

Finally, the findings of this case report indicated that G-CSF produced by head and neck cancer may promote the occurrence of vertebral fracture and splenomegaly. Therefore, serum G-CSF produced by tumor cells may be associated with various systemic complications.

\section{Acknowledgements}

Not applicable.

\section{Funding}

No funding was received.

\section{Availability of data and materials}

The datasets used and/or analyzed during the present study are available from the corresponding author on reasonable request.

\section{Authors' contributions}

$\mathrm{NK}, \mathrm{SS}, \mathrm{KK}$ and $\mathrm{KN}$ treated the patient, analyzed the raw data and wrote the manuscript; ES, MD and TY reviewed and edited the manuscript. All the authors were involved in the preparation of the manuscript and have approved the final manuscript.

\section{Ethics approval and consent to participate}

The present study was approved by our institutional Ethics Committee and written informed consent was obtained from the patient. 


\section{Patient consent for publication}

The patient and her family have provided their written informed consent to the publication of the case details and associated images, provided the patient's anonymity is protected.

\section{Competing interests}

The authors declare that they have no competing interests.

\section{References}

1. Kaneko N, Kawano S, Matsubara R, Goto Y, Jinno T, Maruse Y, Sakamoto T, Hashiguchi Y, Iida M and Nakamura S: Tongue squamous cell carcinoma producing both parathyroid hormone-related protein and granulocyte colony-stimulating factor: A case report and literature review. World J Surg Oncol 14: 161, 2018.

2. Asano S, Urabe A, Okabe T, Sato N and Kondo Y: Demonstration of granulopoietic factor(s) in the plasma of nude mice transplanted with a human lung cancer and in the tumor tissue. Blood 49: 845-852, 1977.

3. Yakisan E, Schirg E, Zeidler C, Bishop NJ, Reiter A, Hirt A, Riehm $\mathrm{H}$ and Welte $\mathrm{K}$ : High incidence of significant bone loss in patients with severe congenital neutropenia (Kostmann's syndrome). J Pediatr 131: 592-597, 1997.

4. Takamatsu Y, Simmons PJ, Moore RJ, Morris HA, To LB and Lévesque JP: Osteoclast-mediated bone resorption is stimulated during short-term administration of granulocyte colony-stimulating factor but is not responsible for hematopoietic progenitor cell mobilization. Blood 92: 3465-3473, 1998.

5. Sidan L, Tianshou L, Yongbing C, Yinchao N, Changhong L, Lanting L, Qiaochuan L and Lugui Q: Granulocyte colonystimulating factor induces osteoblast inhibition by B lymphocytes and osteoclast activation by $\mathrm{T}$ lymphocytes during hematopoietic stem/progenitor cell mobilization. Biol Blood Marrow Transplant 21: 1384-1391, 2015.

6. Turhan AB, Binay C, Bor O and Simsek E: The effects of short-term use of granulocyte colony-stimulating factor on bone metabolism in child cancer patients. Norh Clin Istanb 5: 277-281, 2018.

7. Goshen E, Tima Davidson T, Yeshurun M and Zwas ST: Combined increased and decreased skeletal uptake of F-18 FDG. Clin Nucl Med 31: 520-522, 2006.

8. Christopher MJ and Link DC: Granulocyte colony-stimulating factor induces osteoblast apoptosis and inhibits osteoblast differentiation. J Bone Miner Res 23: 1765-1774, 2008.

9. Kusumahstuti KP, Watabe T, Kitamura N and Yamamoto T: Diffuse bone marrow uptake related to granulocyte colony-stimulating factor-producing maxillary sinus carcinoma on 4-borono-2-18F-fluoro-L-phenylalanine positron emission tomography/computed tomography. World J Nucl Med 20: 188-191, 2021.

10. Morooka M, Kubota K, Murata Y, Shibuya H, Ito K, Mochizuki M, Akashi T, Chiba T, Nomura T, Ito H and Morita T: (18)F-FDG-PET/CT findings of granulocyte colony stimulating factor (G-CSF)-producing lung tumors. Ann Nucl Med 22: 635-639, 2008
11. Kuroshima T, Wada M, Sato T, Takano M and Makino S: G-CSF producing oral carcinoma with diffuse uptake of FDG in the bone marrow: A case report. Oncol Lett 15: 1241-1245, 2018.

12. Pfister DG, Spencer S, Adelstein D, Adkins D, Anzai Y, Brizel DM, Bruce JY, Busse PM, Caudell JJ, Cmelak AJ, et al: Head and Neck Cancers, Version 2.2020, NCCN Clinical Practice Guidelines in Oncology. J Natl Compr Canc Netw 18: 873-898, 2020.

13. Picardi M, Rosa GD, Selleri C, Scarpato N, Soscia E, Martinelli V, Ciancia R and Rotoli B: Spleen enlargement following recombinant human granulocyte colony-stimulating factor administration for peripheral blood stem cell mobilization. Haematologica 88: 794-800, 2003.

14. Al-Khinji A and Linenberger M: Splenic infarction and G-CSF. Transfusion 55: 708, 2015.

15. Aubrey-Bassler FK and Sowers N: 613 cases of splenic rupture without risk factors or previously diagnosed disease: A systematic review. BMC Emerg Med 12: 11, 2012.

16. Alshamrani MA, Al-Foheidi $\mathrm{M}$ and Abdulrahim $\mathrm{AH}$ : Granulocyte colony stimulating factor (G-CSF) induced splenic infarction in breast cancer patient treated with dose-dense chemotherapy regimen. Case Rep Oncol Med 8174986, 2019.

17. Stroncek D, Shawker T, Follmann D and Leitman SF: G-CSF-induced spleen size changes in peripheral blood progenitor cell donors. Transfusion 43: 609-613, 2003.

18. Pitini V, Ciccolo A, Arrigo C, Aloi G, Micali C and Torre FL: Spontaneous rupture of spleen during periferal blood stem cell mobilization in a patient with breast cancer. Haematologica 85: $559-560,2000$

19. Masood N, Shaikh AJ, Memon WA and Idress R: Splenic rupture, secondary to G-CSF use for chemotherapy induced neutropenia: A case report and review of literature. Cases J 24: 418, 2008.

20. de Wolff JF, Planken EV and den Ottolander GJ: Extreme leucocytosis and splenomegaly in metastasized melanoma. Neth $\mathrm{J}$ Med 62: 164-167, 2004.

21. Tsuruta N, Yatsunami J, Takayama K, Nakanishi Y, Ichinose Y and Hara N: Granulocyte-macrophage-colony stimulating factor stimulates tumor invasiveness in squamous cell lung carcinoma. Cancer 82: 2173-2183, 1998.

22. Tomita T, Fujii M, Tokumaru Y, Imanishi Y, Kanke M, Yamashita T, Ishiguro R, Kanzaki J, Kameyama K and Otani Y: Granulocyte-macrophage colony-stimulating factor upregulates matrix metalloproteinase-2 (MMP-2) and membrane type-1 MMP (MT1-MMP) in human head and neck cancer cells. Cancer Lett 156: 83-91, 2000.

23. Sugimoto C, Fujieda S, Sunaga H, Noda I, Tanaka N, Kimura Y, Saito $\mathrm{H}$ and Matsukawa S: Granulocyte colony-stimulating factor (G-CSF)-mediated signaling regulates type IV collagenase activity in human head and neck cancer cells. Int J Cancer 93: 42-46, 2001. 